\title{
Treatment of Printing and Dyeing Wastewater by Modified Montmorillonite
}

\author{
Meng-tao Wang, You-li Feng ${ }^{*}$, Cong Wang, Ning Mao \\ School of Resources and Environment, Henan Polytechnic University, Jiaozuo, China \\ Email address: \\ fengyouli66@163.com (You-li Feng),2932403066@qq.com (Meng-tao Wang) \\ ${ }^{*}$ Corresponding author
}

To cite this article:

Meng-tao Wang, You-li Feng, Cong Wang, Ning Mao. Treatment of Printing and Dyeing Wastewater by Modified Montmorillonite. American Journal of Physical Chemistry. Vol. 6, No. 3, 2017, pp. 37-41. doi: 10.11648/j.ajpc.20170603.11

Received: March 31, 2017; Accepted: April 18, 2017; Published: June 3, 2017

\begin{abstract}
The composition of printing and dyeing wastewater is very complex, which is characterized by high alkalinity, color depth, organic matter and more. At present, the commonly used method for treating printing and dyeing wastewater is expensive and the scope of use is limited. This article focuses on the study of montmorillonite. Through the modification of montmorillonite to greatly increase its adsorption performance, and the treatment of printing and dyeing wastewater has a significant effect. The validation of the experiment provides a better solution for the treatment of printing and dyeing wastewater.
\end{abstract}

Keywords: Printing and Dyeing Wastewater, Adsorption Performance, Modified Montmorillonite, Significant Results

\section{Analysis of Composition of Printing and Dyeing Wastewater}

The composition of the printing and dyeing wastewater and the processing of different fibers used in dyes, additives, machinery and equipment and operation methods vary. All kinds of different fibers (cellulose fiber, protein fiber, synthetic fiber) used in the dye and additives pollution caused by the following components: Direct dyes used as additives: $\mathrm{Na}_{2} \mathrm{CO}_{3}, \mathrm{NaCl}, \mathrm{Na}_{2} \mathrm{SO}_{4}$, surfactants; The dyes used in the reactive dyes are: $\mathrm{NaOH}, \mathrm{Na}_{2} \mathrm{CO}_{3}, \mathrm{Na}_{2} \mathrm{SO}_{4}, \mathrm{NaCl}$, surfactants; The dyes used for the reduction of dyes are: $\mathrm{NaOH}, \mathrm{Na}_{2} \mathrm{SO}_{4}$, $\mathrm{Na}_{2} \mathrm{Cr}_{2} \mathrm{O}_{7}, \mathrm{H}_{2} \mathrm{O}_{2}, \mathrm{NaBO}_{3}, \mathrm{CH}_{3} \mathrm{COOH}$, surfactants; Sulfide dyes used as additives: $\mathrm{Na}_{2} \mathrm{~S}, \mathrm{Na}_{2} \mathrm{CO}_{3}, \mathrm{NaCl}, \mathrm{H}_{2} \mathrm{O}_{2}$, Ice dyes used additives: $\mathrm{NaOH}, \mathrm{NaNO}_{2}, \mathrm{HCl}$, soap and other surfactants; Pigments used by the additives: pulp, adhesives, resins and so on. Acid dyes used as additives: $\mathrm{CH}_{3} \mathrm{COOH}$, $\left.\mathrm{CH}_{3} \mathrm{COONa}, \mathrm{Na}_{2} \mathrm{SO}_{4}, \mathrm{CH}_{3} \mathrm{COONH}_{4},\left(\mathrm{NH}_{4}\right)_{3} \mathrm{PO}_{4}, \mathrm{NH}_{4}\right)_{2} \mathrm{SO}_{4}$, surfactants; Weak acid dyes used as additives: $\mathrm{CH}_{3} \mathrm{COOH}$, $\mathrm{CH}_{3} \mathrm{COONa}$, surfactants; Neutral dyes used as additives: $\left(\mathrm{NH}_{4}\right)_{2} \mathrm{SO}_{4}$, surfactants; Acid mordant dye used by the additives: $\mathrm{Na}_{2} \mathrm{Cr}_{2} \mathrm{O}_{7}, \mathrm{CH}_{3} \mathrm{COOH}, \mathrm{Na}_{2} \mathrm{SO}_{4}$, surfactants. Disperse dyes used as additives: Dyeing agent, $\mathrm{CH}_{3} \mathrm{COOH}$, $\mathrm{CH}_{3} \mathrm{COONa}$, surfactants; Acid dyes Nylon used in the additives are: $\mathrm{Na}_{2} \mathrm{SO}_{4}$, organic acids, tannic acid, tartaric acid, surfactants; Cationic dyes used in acrylic dyeing auxiliaries are: organic acids, surfactants. In addition to this also includes a large number of printing on the waste. It can be seen that the composition of printing and dyeing wastewater is indeed very complex and difficult to deal with [1].

\section{Research and Modification of Montmorillonite}

\subsection{Research Status of Montmorillonite}

At present, the research on montmorillonite mainly lies in several aspects:

a) Purification of natural bentonite: Pillared montmorillonite in the preparation process of the purity of bentonitedemanding, requiring lower impurity content, cation exchange capacity of $75-100 \mathrm{meq} / 100 \mathrm{~g}$ soil. Due to the different content of montmorillonite in natural Pengrun soil, bentonite must be purified before deep processing to improve the purity of montmorillonite. Montmorillonite purification methods are many, commonly used for physical methods.

b) Montmorillonite pillars: Because montmorillonite has a good ion exchange capacity, it can with many inorganic, organic cation exchange. The physical properties of the montmorillonite after pillared are obviously improved, and the 
interlayer spacing is also greatly improved. The montmorillonite obtained by organic pillar is generally called organic montmorillonite or organic bentonite. The montmorillonite supported by the multi-core polymerization of inorganic metal ions is called hydroxy metal pillared montmorillonite.

c) The application pillared montmorillonite: As the pillared montmorillonite has a good adsorption capacity, in the waste water pollutants adsorption, chemical reaction catalysis and pharmaceutical carriers, etc. have a very wide range of applications. The catalytic properties of the pillared montmorillonite are mainly based on their large specific surface area, large and stable open pores, and highly active and highly acidic surfaces. In the cracking reaction, it can improve the conversion and selectivity, and in the heavy oil cracking has better thermal stability. The catalyst prepared with certain types of pillared montmorillonite catalyst for gasoline selectivity and cracking is higher than that of Y-type zeolites, and the catalyst prepared by mixing such pillared montmorillonite with zeolite can more effectively increase the gasoline Of the yield. Pillared montmorillonite has a good selectivity for certain chemicals. Al-pillared montmorillonite has a good adsorption effect on heavy metals such as $\mathrm{Ni}^{2+}, \mathrm{Cu}^{2}$ ${ }^{+}, \mathrm{Cd}^{2+}$, and can be used as curing agents for these heavy metal contaminants. In addition, Al-pillared montmorillonite has a selective adsorption effect on certain organic compounds, and therefore has potential for organic waste treatment. Pillared montmorillonite for nuclear waste treatment is the result of research in recent years. Al-pillared montmorillonite is freeze-dried and calcined at $500^{\circ} \mathrm{C}$ to obtain porous materials with pore size in the medium (2-20nm). After treatment with $\mathrm{NH}_{3}{ }^{+}$and $\mathrm{Na}^{+}$, the cation exchange capacity can be restored to of the $70 \%$. The resulting pillared montmorillonite has a rapid adsorption of $\mathrm{Sr}^{2+}$ and $\mathrm{Cs}^{+}$radioactive ions, demonstrating its potential for application in radioactive nuclear waste disposal. [2]

\subsection{Montmorillonite Mineral Structure}

Montmorillonite is bentonite the main mineral composition, the content of bentonite is generally $20 \%$ to $90 \%$. Montmorillonite was first discovered in the vicinity of Montmorillon in France, so this name is named montmorillonite. The theoretical chemical formula of montmorillonite is $\mathrm{Al}_{2} \mathrm{O}_{3} \cdot 4 \mathrm{SiO}_{2} \cdot \mathrm{nH}_{2} \mathrm{O}$ ( $\mathrm{n}$ is usually greater than 2), regardless of whether $\mathrm{AL}^{3+}$ and $\mathrm{Si}^{4+}$ in the lattice are replaced by other ions. Its crystal structure is $\mathrm{Al}_{4}\left(\mathrm{Si}_{8} \mathrm{O}_{20}\right)(\mathrm{OH})_{4} \cdot \mathrm{nH}_{2} \mathrm{O}$, the theoretical chemical composition: $\mathrm{SiO}_{2} 66.7 \%, \mathrm{Al}_{2} \mathrm{O}_{3} 25.3 \%, \mathrm{H}_{2} \mathrm{O} 5 \%$. Montmorillonite crystal structure is monoclinic system, is composed of two layers of the top of the connection of silicon tetrahedron in the middle of a layer of aluminum oxide octahedron, the two by the common oxygen atoms connected by the composition of 2 : Type 1 layered silicate minerals [3]. General natural montmorillonite particles are composed of 15 to 20 layers of intertwined layers, and the layers slide with each other. The top of the tetrahedron is directed to the center of the structural layer and is shared with the octahedron, and the three layers are joined together.

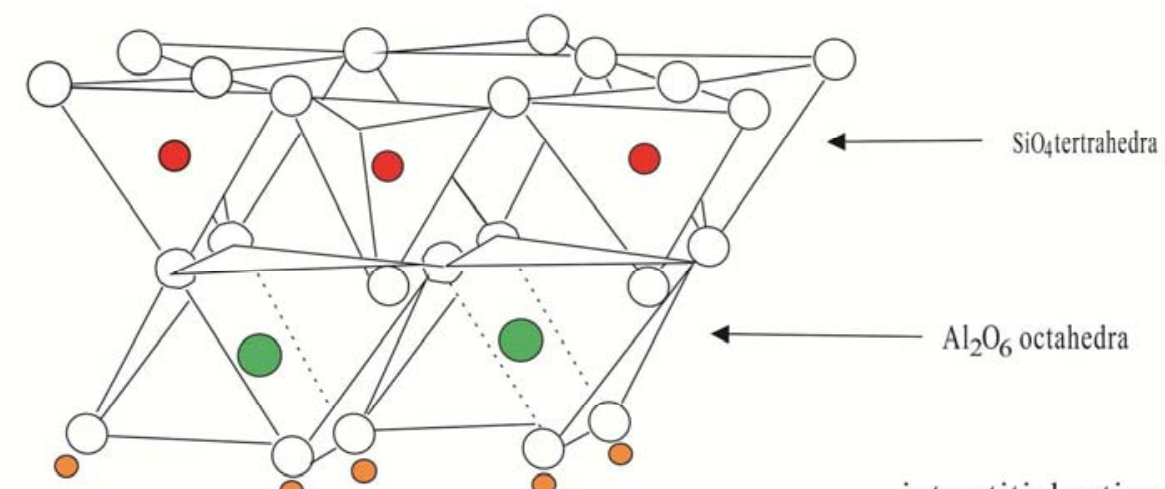

interstitial cations, $\mathrm{H}_{2} \mathrm{O}$

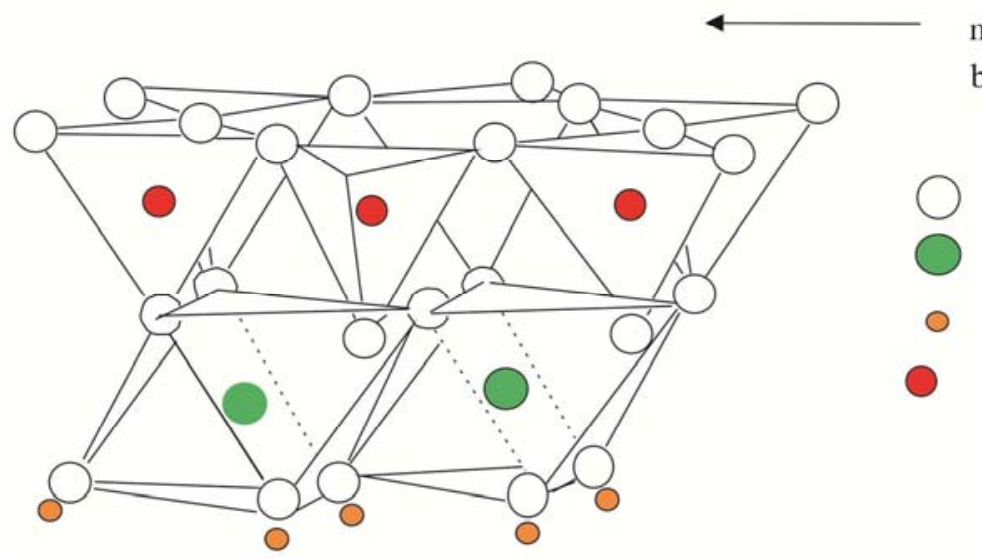

molecules and hydrogen

bonds joining layers

oxygen

aluminum

hydrogen

silion

Figure 1. Crystal structure of montmorillonite mineral. 


\subsection{The Modification Mechanism of Montmorillonite}

Montmorillonite is a clay mineral with a 2: 1 layer structure. The crystal structure is: $(\mathrm{Ca}, \mathrm{Na})\left(\mathrm{Si}_{4-\mathrm{x}} \mathrm{Al}_{\mathrm{x}}\right)(\mathrm{Al}, \mathrm{Fe}, \mathrm{Mg})_{3} \mathrm{O}_{10}$ $(\mathrm{OH})_{2}$. It consists of two layers of $\mathrm{Si}_{-} \mathrm{O}_{4}$ tetrahedral layer sandwich a layer of $\mathrm{Al}(\mathrm{Mg}, \mathrm{Fe})-\mathrm{O}_{6}$ octahedral layer composed of basic structural unit layer. As the $\mathrm{Si}-\mathrm{O}_{4}$ tetrahedron is partially replaced by $\mathrm{Al}-\mathrm{O}_{4}$ tetrahedra, the electrostatic imbalance in the structural unit layer is introduced, so that the low-cost, large-diameter cation $\mathrm{Ca}^{2+}$, $\mathrm{Mg}^{2+}, \mathrm{Na}^{+}$and so on are introduced between the layers, and are balanced by remote electrostatic balance The excess negative price in the structural unit layer. These low valence, large radius of ions and structural elements between the weak layer of the interlayer cation is interchangeable. The strong hydration of these layers of cations also allows the layers to adsorb a large amount of water molecules. The montmorillonite minerals are ionized in the aqueous solution and the constituent elements are negatively charged. While the edge of the structural element layer is due to the $\mathrm{Si}-\mathrm{O}$ bond, the Al-O bond is positively charged. Montmorillonite mineral grain is small, with a large surface area, and because the interlayer force is weak, under the action of the solvent, the layers can be peeled, expanded, separated into thinner single crystal, and montmorilloniteHas a large internal surface area. Montmorillonite charge and a huge surface area to make it a strong adsorption [4]. Adsorption is a widely studied process for removing contaminants from aqueous effluents where different types of porous materials were applied. In particular, the adsorption capacity of montmorillonite (Mt) towards different contaminants has been largely studied. The main reasons that turn Mt into important adsorbents are (i) its external negative charge, which makes them particularly useful for removing cationic compounds from water, and (ii) its large total specific surface area, which allows them to anchor and concentrate a high amount of molecules and ions on both outer and inner surfaces [5]. Water-soluble neutral polar organic molecules can replace montmorillonite interlayer water, either with exchangeable cations, or are loosely immobilized between solvent membranes, and organic cations can replace montmorillonite minerals In the inorganic exchange of cations, and firmly combined to form a parent organic matter between the interlayer. While the organic anions adsorbed on the edge of the particles. High molecular weight and nonionic polymers tend to adsorb on the surface of the particles. The adsorption of montmorillonite clay and organic matter occurs through the outer surface of the montmorillonite, the adsorption of the inner surface and the ion exchange. The ability of montmorillonite to adsorb organic matter is closely related to the degree of dispersion of montmorillonite in water, association state and exchangeable ion type [6]. The chemical composition of unmodified montmorillonite is mainly $\mathrm{SiO}_{2}, \mathrm{Al}_{2} \mathrm{O}_{3}, \mathrm{Fe}_{2} \mathrm{O}_{3}$, $\mathrm{MgO}, \mathrm{CaO}, \mathrm{Na}_{2} \mathrm{O}$ and $\mathrm{K}_{2} \mathrm{O}$, and the interlayer exchangeable cations are mainly $\mathrm{Ca}^{2+}$ and $\mathrm{Na}^{+}$[7]. The unmodified montmorillonite clay minerals are dispersed in the aqueous dispersion medium and partially dissociated under the action of the surface double layer. However, due to the existence of exchangeable $\mathrm{Ca}^{2+}, \mathrm{Mg}^{2+}$ ions, part of montmorillonite is still aggregated aggregates [8].

\section{Processing of Printing and Dyeing Wastewater}

\subsection{The Current Treatment of Domestic Printing and Dyeing Wastewater}

Organic printing and dyeing wastewater is a wide source of industrial waste water. Because the water contains a variety of toxic dyes and additives, direct emissions on human harm, domestic and international treatment of printing and dyeing wastewater are very important. However, due to the complicated and variable water quality of the printing and dyeing wastewater, the discharge is large, which brings great difficulties to the treatment and treatment of the printing and dyeing wastewater, and needs to further study and explore the technology with good effect and low cost. At present, at home and abroad in the printing and dyeing wastewater treatment research and development has made great progress, the idea has two aspects: On the one hand is the general type of water treatment coagulants, such as poly aluminum, poly iron, polysilicate, etc., they are through the electrostatic neutralization, adsorption bridge and other functions to achieve the purpose of decolorization and removal of harmful ingredients; On the other hand is the development of specific structure of the dye for the dye or complex reaction to remove the chroma, such as the use of activated carbon adsorption method for the depth of printing and dyeing wastewater treatment, with a simple process, easy to operate and other advantages, but because Activated carbon is expensive, the regeneration process is complex, so the cost is higher, thus limiting the use of activated carbon range. Adsorption method is mainly the use of porous material grinding or particle surface adsorption of waste water in the dye and additives and other pollutants. The method has the advantage of simplifying the investment. According to the principle of adsorption treatment of wastewater, the choice of adsorbent and adsorbent regeneration ability is the main consideration in the practical application of the two points. Activated carbon, industrial waste (such as cinder), natural plant waste (such as charcoal) and synthetic resin is currently the main commonly used adsorbent [9]. Domestic use of attapulgite, organic modified natural zeolite and other organic printing and dyeing wastewater treatment research, but most are still in the experimental research stage.

Printing and dyeing wastewater treatment methods are mainly physical and chemical and biochemical method. Materialization method is the combination of physical and chemical methods, biochemical method is the combination of biological and chemical methods. A single treatment method 
is generally difficult to achieve the desired treatment effect, mixed treatment method is significantly stronger than the single treatment method. Physical treatment methods, including adsorption, membrane separation technology, electronic decolorization technology, extraction technology, magnetic separation method. The most widely used in the physical treatment method is the adsorption method, which is suitable for the deep treatment of low concentration printing and dyeing wastewater. The cost is low and the decolorization effect is good, which is suitable for the treatment of small and medium-sized dyeing and printing plant wastewater. Membrane separation is one of the most commonly used methods for treating printing and dyeing wastewater. It means that in the wastewater treatment, molecules of different particle sizes pass through the semipermeable membrane, so as to achieve selective separation. Membrane separation technology is purely physical process, the membrane does not change phase, without adding catalyst, running low cost. However, the one-time cost of the film is high and the pollution is serious. Different pretreatment methods are selected according to the type of the waste water. Properly remove the suspended solids at the pretreatment time to increase the service life of the membrane, but increase the cost The extraction method mainly uses the organic matter in water and in the organic solvent solubility difference, then the extractant and the pollutant separation, may use the extraction agent, the pollutant can also be further processed after turning waste into treasure. Liquid film technology is one of the rapid development methods in recent years, and can extract dye material in dye-containing wastewater. Magnetic separation technology is a new type of water treatment technology, mainly in the water particles in the magnetic particles after the separation. Chemical method is the main method of treating dye wastewater, mainly based on the principle and method of chemical reaction to separate the waste water in the waste, or change the nature of the wastewater, the harmless treatment of wastewater. There are flocculation and sedimentation methods, chemical oxidation (Fenton method, ozonation method, combined oxidation method), electrochemical method, photochemical oxidation method. Flocculation method is the use of flocculants to dye molecules and other types of impurities for adsorption, flocculation, sedimentation, in the form of sludge discharge, purification of printing and dyeing wastewater, commonly used flocculants are iron, aluminum, magnesium, organic polymer And biopolymers. Chemical oxidation method is divided into Fenton reagent method, ozonation method and the current development of the combined oxidation method. Electrochemical method is through direct or indirect electrolysis, the waste water in the pollutants to remove or toxic substances into non-toxic or low toxicity, the use of small equipment, small footprint, simple operation and management, COD removal rate, bleaching Good results. According to the different ways of electrode reaction, electrochemical method can be subdivided into electrical floatation, electrocoagulation, internal electrolysis, electrocatalytic oxidation and high voltage pulse electrolysis [10].

\subsection{Treatment of Printing and Dyeing Wastewater by Modified Montmorillonite}

The weak acid deep blue GR dubbed the concentration of $0.0250 \mathrm{~g} / \mathrm{L}$ of simulated dye wastewater, accurately weighed a certain quality of the various pillared montmorillonite in $250 \mathrm{ml}$ stoppered conical flask, with a pipette to remove $25.00 \mathrm{~mL}$ of the weak acid Deep blue GR solution, sealed after constant temperature shaking $1.0 \mathrm{hr}$, high-speed centrifugation $10 \mathrm{~min}$, take the supernatant with visible spectrophotometric determination of residual weak acid deep blue GR content, to calculate the pillared montmorillonite weak acid dye removal rate. The results are shown in Table 1

Table 1. The relation between removalpercentage of Weak Deep Blue GR and the amount of pillared montmorillonites.

\begin{tabular}{llllll}
\hline $\begin{array}{l}\text { Amount of } \\
\text { montmorillonite/g }\end{array}$ & $\mathbf{0 . 0 1 0 0}$ & $\mathbf{0 . 0 1 5 0}$ & $\mathbf{0 . 0 2 0 0}$ & $\mathbf{0 . 0 2 5 0}$ & $\mathbf{0 . 0 3 0 0}$ \\
\hline Natural bentonite & 4.0 & 4.0 & 4.3 & 4.2 & 4.3 \\
Na-montmorillonite & 7.8 & 8.4 & 8.1 & 8.6 & 8.7 \\
Al-montmorillonite & 71.4 & 72.7 & 74.0 & 84.7 & 88.3 \\
Fe-montmorillonite & 30.5 & 44.5 & 55.9 & 71.8 & 84.5 \\
OH-Al-montmorillonite & 86.5 & 94.9 & 97.1 & 97.3 & 95.9 \\
OH-Fe-montmorillonite & 60.0 & 83.5 & 91.0 & 95.1 & 96.0 \\
\hline
\end{tabular}

Analysis Table 1 Data:

a) Natural swelling of the organic dye adsorption capacity is very weak, the removal rate of less than $10 \%$, purified sodium Na-montmorillonite on the weak acid deep blue GR removal rate is also very low, about $10 \%$. Because of the natural bentonite, or Na-montmorillonite, the layers are filled with exchangeable inorganic cations such as yellow $\mathrm{Na}^{+}, \mathrm{K}^{+}, \mathrm{Al}^{3+}$, $\mathrm{Ca}^{2+}$ making their hydrophilic ability, but the ability of the parent organism is poor, so the organic dye is weak Acid deep blue GR adsorption capacity is poor.

b) Al-montmorilloniteand Fe-montmorillonite prepared by pure aluminum and iron ion have good adsorption capacity, such as treatment with $0.0250 \mathrm{~g}$ Al-montmorillonite $25 \mathrm{ml}$ weak acidity of $0.0250 \mathrm{~g} / \mathrm{L}$ Deep blue GR solution, the dye removal rate can reach $84.7 \%$. $\mathrm{Al}^{3+}, \mathrm{Fe}^{3+}$ can be hydrolyzed in aqueous solution to form $\left[\mathrm{Al}\left(\mathrm{H}_{2} \mathrm{O}\right)_{6}\right]^{3+},\left[\mathrm{Fe}\left(\mathrm{H}_{2} \mathrm{O}\right)_{6}\right]^{3+}$ and so on, which can be explained by the good flocculation and lack of electron structure from $\mathrm{A}^{3+}$ and $\mathrm{Fe}^{3+}$ Cationic, while the dye waste water colloid is usually a negative charge, $\zeta$ potential between-7 -20mV. These hydrated cations neutralize their surface charges to form coarse flocs, which are precipitated onto the surface of montmorillonite and removed by centrifugation.

c) $\mathrm{OH}-\mathrm{Al}-$, $\mathrm{OH}-\mathrm{Fe}-$ pillared montmorillonite has better ability to adsorb organic dye pollutants, such as: $0.0150 \mathrm{~g}$ $\mathrm{OH}-\mathrm{Al}$-montmorillonite $25 \mathrm{ml}$ concentration of $0.0250 \mathrm{~g} / \mathrm{L}$ if acidic deep blue GR The adsorption removal rate reached $94.9 \%$. On the one hand, due to $\mathrm{Al}^{3+}, \mathrm{Fe}^{3+}$ under the action of alkaline solution can be formed as multi-core hydroxyl polymer aluminum, multi-core hydroxyl polymer iron and other inorganic macromolecules, these ions can absorb weak acid deep blue GR particles, or react with, resulting in flocculation, Its agglomeration and removal; On the other hand, the interlayer spacing of $\mathrm{OH}-\mathrm{Al}$-montmorillonite is 
$18.87 \AA$ due to the increase of interlayerspacing of OH-Al- and $\mathrm{OH}-\mathrm{Fe}$-pillared montmorillonite, $\mathrm{OH}-\mathrm{Fe}-$ montmorillonite $\mathrm{D}$ (001) up to $81.8 \AA$, the interlayer spacing increases, the specific surface area also increases, thus allowing more dye molecules into the interlayer.

d) The adsorption capacity of Fe-montmorillonite is weaker than that of A1-montmorillonite, and the adsorption capacity of OH-Fe-montmorillonite is weaker than $\mathrm{OH}-\mathrm{A} 1$-montmorillonite. First, $\mathrm{Al}^{3+}$ is a better Lewis acid than $\mathrm{Fe}^{3+}$, because $\mathrm{A}^{3+}$ is smaller than $\mathrm{Fe}^{3+}$ radius, resulting in a larger charge density, with greater adsorption-flocculation effect; Second, although the interlayer spacing of $\mathrm{OH}-\mathrm{Al}-\mathrm{montmorillonite}$ is less than that of $\mathrm{OH}-\mathrm{Fe}$-montmorillonite, the proportion of $\mathrm{OH}-\mathrm{Al}$-montmorillonite is high and thus has a larger specific surface area.

\section{Conclusion}

The experimental results show that the removal rate of modified montmorillonite is much higher than that of natural montmorillonite, especially the hydroxyl metal pillared montmorillonite is about $90 \%$. Hydroxyl metal pillared montmorillonite has good adsorption properties, can be used for organic dyes or other organic pollutants treatment.

\section{References}

[1] Yi-fei CHEN, Cheng-liang SHI. Price Analysis and Purification Technology of Printing and Dyeing Wastewater [J]. Sichuan Silk, 2002, (01), 15-17.
[2] Yu-zhen Wu, Qian Zhang, Shun Yang, Qian Zhou, Qi-fu Xu. Study on the Adsorption of Methicillin by Modified Montmorillonite [J]. Progress in Chemical Industry. 2017 (02): 618-625.

[3] Rui Cao, An-long Zhang, Sen Wang. Preparation of modified montmorillonite and its adsorption on phenol [J]. Industrial Water Treatment, 2013, (10): 52-55.

[4] Tian-hu CHEN, Jia-quan WANG. Study on Treatment of Dyeing Wastewater by ModifiedMontmorillonite Clay Adsorbent [J]. China Environmental Science, 1996, (01): 60-63.

[5] Martina Gamba, PetrKovář, MiroslavPospíšil, Rosa M. Torres Sánchez. Insight into thiabendazole interaction with montmorillonite and organically modified montmorillonites [J]. Applied Clay Science, 2017, 137: 59-68.

[6] Xian-ming Zheng. Preparation of organic bentonite and its process selection [J]. Non-metallic mineral, 1991, (06): 27-29.

[7] Xiao-hui REN, Han-jin LUO, Zi-long ZHANG, Bing-jie HU, Qi-en CHEN. Examination properties of As (V) by hydroxyaluminum and composite modified montmorillonite $[\mathrm{J}]$. Chinese Journal of Environmental Engineering, 2013, (05): 1702-1708.

[8] Hui-minFeng, Xia He. Application of JDF Montmorillonite Clay Gel and Its Application in Cosmetics [J]. Non-metallic Mineral, 1991, (02): 32-34.

[9] Feng-mei Chen. Characteristics of Dyeing Wastewater in Environmental Engineering and Its Treatment [J]. Chemical Management, 2016, (13): 101-102.

[10] Wen-yan Li, Shu-rui Liu, Ming-yu Zhang. Progress in dyeing wastewater treatment technology [J]. Journal of Chengdu Textile College, 2016, 33 (4): 142-146. 